\title{
Rats, assorted shit and 'racist groundwater': towards extra-sectional understandings of childhoods and social-material processes
}

\section{John Horton}

University of Northampton, Park Campus, Boughton Green Road, Northampton, UK

NN2 7AL john.horton@,northampton.ac.uk

\section{Peter Kraftl}

School of Geography, Earth and Environmental Sciences, University of Birmingham, Edgbaston, Birmingham, UK, B15 2TT p.kraftl@bham.ac.uk

\begin{abstract}
Reflecting on a study of children's outdoor play in a 'white, working class estate' in east London, this paper argues that social-material processes that are characteristically massy, indivisible, unseen, fluid and noxious have, problematically, remained hidden-in-plain-sight within multidisciplinary research with children and young people. For example, juxtaposing qualitative and autoethnographic data, we highlight children's vivid, troubling narratives of swarming rats, smearing excrement, and percolating subsurface flows of water, toxins and racialised affects. In so doing, we develop a wider argument that key theorisations of matter, nature and nonhuman co-presences have often struggled to articulate the indivisibility of socialmaterial processes from contemporary social-political-economic geographies. Over the course of the paper, as children's raced, classed, exclusionary, disenfranchised narratives accumulate, we recognise the urgency of reconciling microgeographical accounts of play and materiality with readings of geographies of social-economic inequalities, exclusions, ethnicities, religions, memorialisations and mortalities. To this end, we initiate an argument for a move from intersectional to extra-sectional analyses that might retain intersectionality's critical and political purchase, whilst simultaneously folding social-material complexities and vitalities into its theorisation.
\end{abstract}

\section{Keywords}

Childhood, play, social materialities, extrasectionality 
Rats, assorted shit and 'racist groundwater': towards extra-sectional understandings of childhoods and social-material processes

\section{Preface: social-material processes, hidden in plain sight}

This paper reflects upon a year-long study of children's outdoor play in an east London borough. As a point of departure, we present a summary table from our end-of-project report.

'Table 10.7' What children and young people (aged 5-13) dislike about their local community (top 5)

\begin{tabular}{||l|l|l||}
\hline \hline Issue & Frequency & Per cent \\
\hline 'Nothing to do' & 636 & 53 \\
\hline Litter/dirt/'poo' & 448 & 37 \\
\hline Traffic & 384 & 32 \\
\hline Graffiti/vandalism & 252 & 21 \\
\hline Teenagers/older kids & 240 & 20 \\
\hline
\end{tabular}

\section{Introduction}

Social scientists engaged in diversely-located community-based research are well-used to seeing empirics like Table 10.7. A table like this can seem a bit ho-hum unremarkable. One's eyes can glaze over, or skip it entirely. Certainly, as geographers engaged in research with children and young people in England, we have produced dozens of tables like this and seen hundreds more. In this context, the finding that litter/dirt/poo are concerns for many children seems oft-repeated, basically uncontentious and hardly-noteworthy. However, in this paper we argue that the perennial, ubiquitous - but often essentially unremarked - empirical presence of litter/dirt/poo in studies of children, young people and communities should prompt two related trajectories of critical-conceptual reflection.

First, we argue that some particular categories of social-materialities are too-often hidden-inplain-sight in multidisciplinary research with children and young people. We contend that social-materialities have frequently had an odd, ambivalent status within this context: being both perennially-present within research findings, but also (like the 'litter/dirt/poo' in Table 
10.7) often reductively-summarised, barely-registered, and certainly doing no kind of justice to children's vivid, visceral, powerfully-affecting, haunting narratives of everyday materialities. In particular we argue that, despite significant 'new waves' of materially-attuned theorisation, much scholarship in Childhood Studies and Children's Geographies retains a characteristic inattentiveness to social-material process, which we critique by highlighting social-materialities which are smearing, swarming and percolating.

Our second, wider, concern is that social scientists working with concepts of matter, nature and nonhuman co-presences have often struggled to articulate relationships between social-material processes and contemporary social-political-economic geographies. We argue that many theorisations of social-materialities could do more to acknowledge the politics, harms, violence and exclusions in(di)visibly co-constituted in/through social-material processes. Conversely, we argue that debates about multiculturalism, conviviality, cosmopolitanism, social class, poverty and austerity might productively be brought into different kinds of conversations with theories of socio-materialities.

The following sections develop these critiques via reflection upon a study of children's outdoor play in north-east London. As we will show (and as was notably not evident from published outputs like Table 10.7), a series of complex, sometimes-upsetting qualitative evocations of social-materiality surfaced in this project. We have found ourselves haunted by these data: because of their poignancy, viscerality and sometimes casual cruelty; because they differ markedly from chief accounts of children and materiality; and perhaps because, in hindsight, our research training - steeped in nonrepresentational and posthumanist cultural geography did not prepare us for encounters with starkly classed and raced inequalities. In the following section this case study is initially framed in relation to recent, rich theorisations of matter, nonhumans and natures within multidisciplinary studies of childhood. We develop an argument that the particular theoretical underpinnings of work in this context have constituted a focus upon particular modes of materialities, and a marked, problematic inattentiveness to socialmaterial processes that are characteristically massy, indivisible, unseen, fluid and noxious. 
Following a contextual overview of the case study project and community, and an orientation to the paper's presentational form, we present three examples of social-material processes which exemplify this massy, indivisible, festering toxicity. We particularly highlight children's vivid, troubling narratives of swarming rats, smearing excrement, and percolating subsurface flows of water, toxins and racialised affects. A central concern of this paper has been to develop an analytic-presentational strategy - juxtaposing 'lumped-together' qualitative data, autoethnographic reflections, found texts, and multidisciplinary theoretical prompts - to convey something of the complexity of these narratives. We hope that what follows might be suggestive of productive ways in which childhood studies scholars and others might come to terms with (what) matters in children's everyday lives in registers overlooked in previous scholarship. More widely, we hope that our presentation of these troubling, caustic, sometimes-nightmarish narratives might open a space in which to articulate both bodily, microgeographical encounters with social-material processes and the structural, political, exclusionary social geographies which are co-constituted in/through them within communities (Horton and Kraftl, 2017). In particular, in the paper's latter sections - as these children's raced, classed, exclusionary, disenfranchised narratives accumulate, and the indivisibility of play, materialities and socialpolitical-economic geographies in this community becomes more evident - we recognise the urgency of reconciling microgeographical accounts of play and materiality with readings of geographies of social-economic inequalities, exclusions, ethnicities, religions, memorialisations and mortalities. To this end, we initiate an argument for a move from intersectional to extrasectional analyses that might retain intersectionality's critical and political purchase, whilst simultaneously folding social-material complexities and vitalities into its theorisation. In conclusion, having moved from the neat, sanitised, foreclosed presentation of findings in Table 10.7 to the vivid, violent, festering social-material processes narrated in the paper's main body, we ask how - conceptually, morally, politically, emotionally - academics within and beyond childhood studies might respond to troubling socio-materialities like smearing-swarmingpercolating. 


\section{Turns to matter, nonhumans and natures}

Researchers within multidisciplinary studies of childhood and youth have often been at the vanguard of engagements with theorisations of matter, nature and nonhuman copresences, particularly via three, interconnected 'new waves' of empirical-theoretical work. However, in relation to each of these lines of work, we argue that some substantial categories of politicised social-material processuality seem to have been poorly accommodated. Developing theorisations of the politics of play (Harker, 2005, Carter et al., 2016, Woodyer et al., 2016), social-materialities (Prout, 2005, Taylor et al., 2012, Rautio 2013a) and childhood and youth (Philo 2000, 2016, Philo and Swanson 2008, Skelton 2013, Häkli and Kallio, 2016) we thus call for a fuller apprehension of politicised materialities-nonhumans-natures within this empiricaltheoretical context.

First, refracting wider theoretical work on materialities, actant networks and material culture, a great deal of social scientific work over the last three decades has foregrounded material spaces, barriers and affordances in children's everyday lives (Kernan, 2010, Änggård, 2016), the significance of transitional, played-with, commodified or popular cultural objects for children and young people (Cross, 1999, Mitchell and Reid-Walsh, 2002), practices of material bricolage within youthful subcultural identity-formations (Russell and Tyler, 2005, Marion and Nairn, 2011), and object-histories indicative of shifting normative constructions of childhood and youth (Derevenski, 2000, Dowling, 2008). While this work has been hugely significant in constituting a demand and lexicon to explore children and young people's material everyday geographies we worry that each approach can lead one to notice and prioritise only some, particular kinds of material objects. They particularly prioritise those materialities characterised by a singular, plainly-visible, divisible, neatly-bounded presence or haecceity: like the shifting, meaningful historical development of $a$ particular toy, or $a$ particular item of classroom furniture. Moreover, we share some emergent critical concerns that work in this context has tended to unduly emphasise material practices which are manifestly meaning-ful and readilynarratable. They may often overlook many ongoing, everyday, moment-by-moment, autotelic, 
intra-active, seemingly pointless or meaning-less experiences of just 'getting along with' materialities (Rautio, 2013a, Rautio and Jokinen, 2016), or the ways in which communities are always already embedded in complex, socio-material, biophysical, ever-processual, often-unsaid landscapes (Jones, 2013, 2015). In the following sections, we want to direct attention to some particular forms or experiences of materialities which are, consequently, often excluded from much work on children's material geographies. In particular, we acknowledge how children's accounts of outdoor play frequently describe materialities that are characteristically murky, massy, out-of-sight, elusive and in-process.

Second, many social scientists have engaged concepts of posthumanism, animality, dwelling and animal geographies to articulate children's encounters with living nonhuman copresences in diverse contexts. Here, work has often foregrounded children's relationships with pets and companion animals (Morrow, 1998, Tipper, 2011), or interspecies encounters in spaces of leisure, tourism or education (Melson, 2005, Änggård, 2010). Work by Taylor and colleagues (Taylor, 2013, Taylor et al. 2012) has latterly been significant in critically expanding the conceptual-empirical repertoire of work in this area. Contra a longstanding tendency to focus upon children's relationships with individualised, charismatic, companionable megafauna, they call for a much-expanded apprehension of 'everyday multispecies common worlds', and the complex, heterogeneous, intra-active (and importantly 'not-always-gorgeous') social natures that are children everyday geographies (Taylor and Pacini-Katchabaw, 2015). We develop this critique through a focus upon children's own narratives of social natures, that proved to be imaginative, vivid, creative, detailed, affecting - and sometimes surreal, noxious, cruel, hurtful, exclusionary - in ways which seem to us to be disregarded in much extant work on children, young people and nonhuman copresences.

Third, developing contemporary debates around environmental education, sustainability, environmental psychology, socio-natures, Anthropocenic geographies and children's mobilities, a longstanding body of social scientific research has considered children's (dis)engagements 
with nature. A considerable, multidisciplinary range of work has sought to evidence children's distanciation from nature, and declining use of outdoor spaces, in many minority world contexts, in spite of the positive health, wellbeing, developmental and pedagogic outcomes of activities in natural, outdoor spaces (Lester and Maudsley, 2007). While this kind of work has been profoundly important in motivating and shaping so much multidisciplinary research with children and young people, we call for openness to alternative, more critical understandings of children and young people's engagements with nature. We worry that too many studies seem to come with a prior, uncritically-normative view of encounters with nature as necessarily, axiomatically positive. Much social scientific work about children and nature entirely overlooks wide-ranging critiques of the social-constructedness and normativity of the concept 'nature', and thus serves to efface or marginalise many non-normative experiences and geographies (Horton, 2016). As this paper will demonstrate, children's everyday narratives can present challenging understandings which unsettle normative discourses of the value of natural, outdoor spaces. As Prout (2005) and Rautio (2013a, 2013b) note, discourses of 'children's encounters with nature' effectively reproduce an understanding of human separateness from nature, overlooking ways in which children and young people are always already co-present with organisms, species, ecologies, nonhuman actants and 'natural' materialities, even in urban or ostensibly-'unnatural' settings. In raising these critiques we do not deny that there is much extant evidence that encounters with natural and outdoor spaces may be affirmatively transformative. However, we do suggest that encounters with nature may also be otherwise. In highlighting details of children's lay narratives of local ecologies, microbiologies and hydrologies, we thus recommend openness to the suggestion that experiences of natural spaces can, sometimes, be troubling, un-idyllic, anxiety-ridden, anxiety-inducing, noxious, nightmarish or brimful of ethical ambiguities, politicised tensions and social exclusions.

In one sense, then, this paper develops an argument that the specific multidisciplinary contexts of Children's Geographies and Childhood Studies could acknowledge a wider range of socialmaterialities: beyond the singular, visible, meaning-ful objects highlighted via their 
engagements with recent theories of matter; beyond the companionable and charismatic fauna and flora prioritised via many readings of theories of nonhuman copresence; and beyond the solely and normatively affirmative or redemptive encounters with natures anticipated by so many contemporary theorisations of nature and outdoor space. For children and young people's everyday geographies are full of material objects which are not necessarily meaning-ful and materialities which are not cleanly visible or neatly narratable; they frequently encounter nonhuman copresences which are unpleasant, pungent or unsettling, or which go altogether unnoticed; and their encounters with natural, outdoor spaces can be deeply haunting, upsetting or anxiety-inducing.

Over the course of the paper we also develop a wider concern that some profuse categories of social-material processuality seem to be poorly accommodated within rich, recent theorisations of materialities-nonhumans-natures. Specifically, we feel that many applications of these concepts constitute a sidelining of social-materialities which are: fluvial and fluid; in-flux and in-process; complex in processuality or intra-agency; hidden or elusive; indivisible or undifferentiated; messy or murky; noxious or hurtful; nightmarish or haunting; hard-to-relate in terms of scale or form; not-necessarily affirmative or normative; and subject to rumour, urban myth and lay narratives. As we relate some of the complex folding of playspaces, substances, organisms, ecologies, hydrologies, politics, exclusions, ethnicities, religions, memorialisations and mortalities within this context, we outline a concept of extra-sectionalities in an attempt to find words to bespeak these caustic, exclusionary politics in/of everyday geographies of play and playspaces.

\section{Encountering social-material processes in research on play in NE London}

Empirically, this paper reflects upon data from a study of children's outdoor play in north-east London. The project was commissioned by a consortium of public and third sector agencies, who specified a focus upon three local, adjacent wards where local outdoor playspaces were reportedly poorly used. Over a twelve month period, we consulted with 1,243 local 5-13-year- 
olds across the three wards. In each area, research was conducted in two schools plus at least two out-of-school youth groups. Participants undertook a range of research activities, which produced a profuse, complex, detailed array of data about local outdoor spaces. This paper focuses upon data from one case study area: part of a large post-war social-housing estate which is among the $20 \%$ most deprived communities in England according to the most recent UK Index of Multiple Deprivation (IMD). The community is labelled a 'white working-class estate' (see Figure 3): in 2011, 63\% of the resident population were white British, $8 \%$ were Polish, and $6 \%$ were British-Indian. The community has undergone recent demographic-cultural change: in the 2001 census, the population was $88 \%$ white British; between 2001 and 2011 the proportion of the population self-identifying as Christian fell from 74 to 55\%, whereas the proportion selfidentifying as Muslim increased from 2 to $10 \%$. As we will describe, the community is located on edge of the Greater London conurbation. A distant tributary of the River Thames runs through and under it and, like many urban edgelands, the community has come to be the site for many unpopular landuses (including waste disposal, sewage works, cemeteries).

We focus upon data from two activities conducted in this community: (i) a detailed questionnaire survey completed by 423 participants; (ii) a follow-up mapping exercise, completed by 120 participants. Contextual information about participants is presented in Table 1.The questionnaire included a mixture of closed and fairly substantial open questions about usage and experiences of local outdoor playspaces. We were on hand to support completion of the survey and, particularly, extend discussions relating to open questions. The subsequent mapping exercise was conducted with small friendship groups, who were asked to place annotated stickers onto a large local area map, indicating experiences and opinions of local playspaces. Qualitative discussions during all activities were transcribed. 


\begin{tabular}{lcccc}
\hline & Survey & & \multicolumn{2}{c}{ Mapping exercise } \\
\hline Gender & Frequency & Per cent & Frequency & Per cent \\
$\quad$ Male & 203 & 48 & 64 & 53 \\
$\quad$ Female & 220 & 52 & 56 & 47 \\
\hline Age & & & & \\
$\quad$ 5-7 years & 76 & 18 & 0 & 0 \\
$\quad$ 8-10 years & 169 & 40 & 50 & 42 \\
$\quad 11-13$ years & 178 & 42 & 70 & 58 \\
\hline Self-defined ethnicity & & & & \\
$\quad$ White British & 173 & 41 & 40 & 32 \\
$\quad$ Pakistani & 34 & 8 & 3 & 3 \\
$\quad$ Indian & 25 & 6 & 3 & 3 \\
$\quad$ Somali & 22 & 5 & 6 & 5 \\
$\quad$ Polish & 21 & 5 & 0 & 0 \\
$\quad$ Bangladeshi & 20 & 5 & 0 & 0 \\
$\quad$ Jamaican & 12 & 3 & 0 & 0 \\
$\quad$ Not indicated & 116 & 27 & 68 & 57 \\
\hline
\end{tabular}

The following sections are structured around three themes which recurred in qualitative data from this community (but which, on reflection, hardly figured in our formal report to project funders). In one sense, as in the prefatory Table 10.7, these responses could be coded - yet again - as evidence that children described dirt/poo/litter as a barrier to outdoor play. However, on reflection we recognise that this kind of finding diminishes and underestimates the ways in which this dirt/poo/litter mattered to participants, and the manner in which they narrated it. For when participants' discussions of dirt/poo/litter are studied more carefully, they reveal a series of narratives which are characteristically complex, troubling, haunting, politicised, exclusionary and - notably - overwhelmingly concerned with social material processes.

In the following sections we reflect upon children's narratives of three constituents of local dirt/poo/litter: smearing excrement, swarming rats and percolating groundwater. Our analyticpresentational strategy is intended to convey the fraught, processual complexity of these narratives. To this end, our analysis entrains and juxtaposes three kinds of text. First, we present children's qualitative responses to our research about local outdoor playspaces. In relation to each theme, qualitative data are lumped-together, en masse, as figures $(2,4$, and 6$)$ in an attempt 
to evoke the massy, affecting social-materialities under discussion, the profuse qualitative data presented to us, and the challenge of making sense of this material. For us, it is in their collective reading - rather than their reduction to statistics, 'codes' or 'indicative' quotations that the sheer, collective messiness and massiness of these socio-materialities becomes evident. Years have passed since our fieldwork - and we have attempted multiple analyses of these data - yet we still find this material challenging. Second, these data are interspersed with photographs and fragments of autoethographic writing generated during our multiple, extended visits to, and walks within, sites mentioned in the paper. We have selected and edited figures 1 , 3 and 5 to contextualise themes, localities and issues discussed by participants. So, the boxed autoethnographic figures direct attention to some distinctive features of the case study community, particularly its geographies of watercourses, its edgeland location in Greater London, and its contested geographies of religion, ethnicity and urban planning. Third, our reflections are both grounded and opened-up via a reading of three theoretical prompts: thus we juxtapose children's narratives of smearing, swarming and percolating with theorisations of fluidity (Neimanis, 2012), urban natures (Whatmore and Hinchcliffe, 2006), and (sub)urban multicultures (Nayak, 2010). We hope that the resulting juxtaposition is productive, both in evoking these children's unsettling narratives of local outdoor playspaces and in articulating the indivisibility of microgeographical social-materialities from exclusionary socialeconomic geographies within communities.

\section{Smearing: 'assorted shit'}

As in many previous studies of children's outdoor play, 'poo' was frequently named as a key concern in local outdoor playspaces (see Figure 2). However, and importantly contra the kinds of reductive analyses typified by our Table 10.7, participants also detained some characteristics of, and experiences of living-with, this 'assorted shit'. Notably, they repeatedly evoked the 'smeared' fluidity-solidity of excrement, and its occurrence within indivisible masses of matter (including multiple forms of excrement, mud, vomit, chewing gum, cigarette ends, and other messy substances of uncertain provenance, as in Figure 1). 


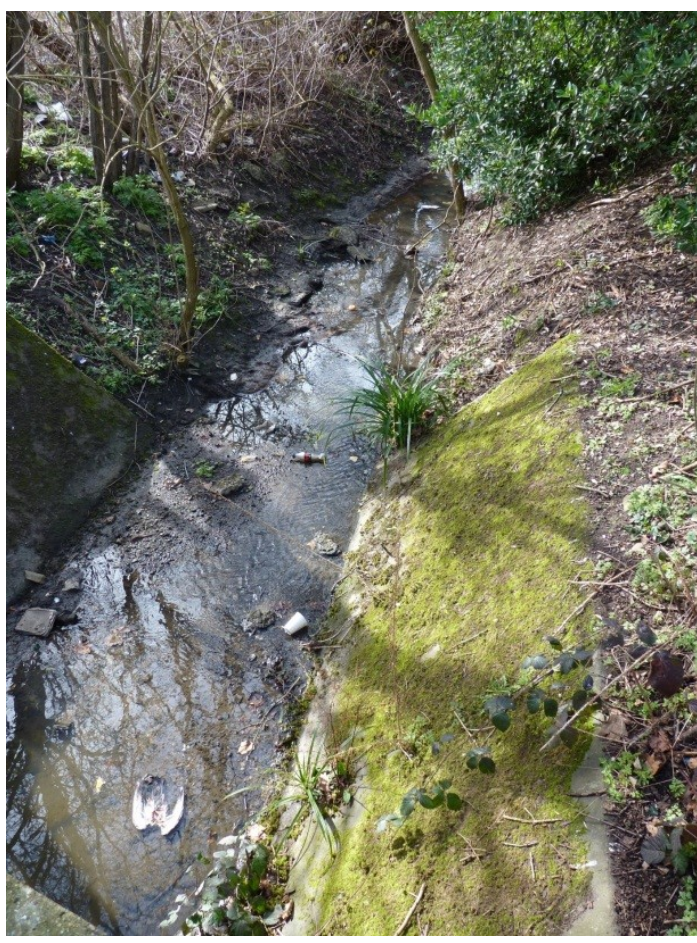

...The community is built on and around a narrow, braided, convoluted, distant tributary of the River Thames. Water figures prominently in children and young people's narratives of outdoor play here. Most designated playspaces lie on streams, water features or wetlands. And many participants' narratives of outdoor play evoke a local geography of channels, mud, drains, weirs, pumping stations, moorings, ropes, ladders, life-saving equipment, warning signs, graffiti-ed waterside brickwork and aquatic wildlife (ducks, geese, herons, mosquitoes, voles). Walking sections of the watercourse, we are struck by two characteristic features. First, the watercourse is elusive, and impossible to walk linearly. The water is culverted and subterranean at many points. It is disorientating and impossible to navigate, even with map in hand. We walk for a while, but the water keeps disappearing (then surfacing in unexpected places). Elsewhere, complex, rusty assemblages of barbed wire, mesh fencing, padlocked gates, anti-climb paint, security spikes and anti-trespass signage keep us at a distance from the water. We can hear the water, but not see it. Second, on and alongside the water, we are constantly aware of a smeared morass of mud, sediment, slime, murk, algae, excrement, eutrophication, moss, rust, leaf litter, waterlogged rubbish, rotting food wrappers, fly-tipped waste, flotsam, oily film, scum, scurf, and occasional dead animals, discarded Christmas trees, paint tins, automotive components and shopping trolleys...

The community, and many of its designated playspaces, are situated adjacent to a tributary of the River Thames. The watercourse presented all kinds of materialities, all-at-once: solid, flowing, watery, oozing, rusting, metallic, algal, animal, plastic, oily, and much more, and these were routinely mentioned in accounts of outdoor play. As in Figure 2, many participants highlighted how these massy social-materialities of 'assorted shit' were noticed on/around playspaces, and registered as smells, sticky surfaces, indistinguishable surface grime, stained trainers and spattered clothing. (And perhaps, in recording these messes in lurid detail, children were playing with $u s$, amused by the opportunity to write about 'poo' in a 'serious', adultinitiated questionnaire). These smeared, smelly social-materialities were often understood to pose an abject, existential threat, particularly to younger children who were figured as especially vulnerable to microbial hazards of 'poo everywhere'. In recounting this threat, participants evoked elements of a lay microbiology of flies, aggressive germs and harmful infections (causing sickness, blindness or death). 


\section{Figure 2 Children and young people on 'poo'}

"Rec ground stinks of poo $=$ dog poo, goose poo, rat poo, people poo. Assorted shit basically all over our park"

"Dog mess is smeared on park and playground everywhere"

"This area ain't clean!! Get rid of litter, dirt and smelly environment - get rid of dumped rubbish. Get rid of so much poo"

"Pick up the litter at every park and everywhere. It is very dirty and people can be sick - piles of sick on the playground. Clean dog poo and chewing gum. POO EVERYWHERE!"

"Really, really, really, really dirty. The amount of rubbish, glass and dog dirt all around is quite shameful",

"Good place for walks (despite mud, dogs and goose excreta!!)"

"The Green is close to home/school but there are often too many beer cans and cigarette ends, and too much dogs' mess too"

"Poo! Poo! It should be cleaner. People could be infected. Trainers get stained with pooey slime"

"POO - Children could walk in it. Dog poo and pigeon poo. Get POO on shoes and clothes"

"STINKS of poo all over the park"

"Dog and duck poo gets on slide and seats. Could harm little ones"

"Lots to do, but dogs often come into the baby section. Dog poo in baby section and when playing football"

"Poo mixed with mud. Bacteria!"

"Poo everywhere - very dangerous for children. Can cause sickness"

"Clean up DOGS' MESS - sort out general cleanliness. Mess can make us sick or even cause death"

"Duck poo - BAD! Dog poo - BAD! Cause flies and disease"

"Poo and litter can be very dangerous for little children. Poo can cause blindness"

"Tidy up - make it more environmentally nice. Less litter, less gangs, less violence, Less poo"

"Should clear up shit, fix broken play equipment. Paint railings. Pick up litter"

"Rec. Ground is unkempt, with teenagers hanging around and dog mess"

"Dog droppings disfigure the local play areas - too many dog owners seem to view the parks as toilets"

"It is sad that our park is treated as a dumping ground with dogshit all over"

"Irresponsible dog owners allow their dogs to mess up the park, but do not clean up after them. Parks need to be cleaned, with more dog toilets/bins"

"Tidy up all poo and litter - we need to be more proud of our park"

"Main thing to change = litter and rubbish around the place. Disgusting. Parks are so dirty - no-one makes the effort to clean them up, so they just get worse. No-one cares"

"Just clean up the mess. Council should get it cleaned up. It should be the law"

"Parks need to be cleaned, with more dog toilets/bins. They don't care about this area"

The problem of 'poo' in local playspaces was portrayed as indivisible from a range of concurrent social-economic-politic problems. Participants frequently mentioned 'poo' in the same breath as issues like litter, disrepair, graffiti, vandalism and - most strikingly - the presence of older teenagers in local playspaces. The presence of 'poo' - and teenagers 'hanging around' - within playspaces was figured as emblematic of malaise within the case study community. For many participants, smeared excrement and teenage gangs were indicative and symptomatic of a 'rotten', 'sick', 'sad', 'disfigured' community which was treated 'as a dumping ground'. In different conversations, this notion of 'dumping ground' could be meant literally (given seemingly-intractable concerns relating to 'fly-tipping' [illegal dumping of 
waste] in secluded streets and spaces adjacent to playpaces) or more figuratively (denoting concerns that policy-makers saw the community as a place where contentious land uses, institutions and populations could be 'dumped'). These excretive materialities were thus 'smeared' with widely-circulating discourses of the community as 'on edge', marginalised and forgotten. The evocation of smeared excrement was frequently accompanied by strong sense that 'something should be done'. Sometimes, this was explained in individualised terms of local residents and dog-owners needing to demonstrate greater neighbourhood pride or responsibility. However, overwhelmingly, the discourse of 'something should be done' about 'poo' was said in a more angry, politicised tone, directed at an absent 'them' - sometimes 'the council' or 'politicians' - who 'should sort it out', but 'no-one cares'. As we will show, this politicised sense of 'no one cares' (sometimes 'no one cares about us' or 'no one cares about this community') was deeply-felt and pervaded talk of all manner of local outdoor spaces.

In highlighting 'smearing', we call attention to complex social-material processes which seem not to correspond to the rather neater nonhuman objects and animal-actants so evident in accounts of children and nonhuman others. We feel that processual, indivisible and smearing forms of social-materialities are not adequately accommodated within this body of work, and consequently we do not yet have a sufficient language to attend to matter that does not readily take the form of a companionable species, and/or which resists categorisation as living or inert. Hence, 'smearing' - as both verb and noun - is a term we highlight in an attempt to witness the massified, spatially-extensive, oozingly dynamic coagulations of water, mud, excrement, algae, decaying flora and fauna, and more, present in our participants' accounts. Smearing thus refers to social-materialities that are more complexly, elusively processual (being, for example, mineralic, microbial, bacterial, atrophying) than the more singular co-presences (like dogs [Tipper, 2011] or kangaroos [Taylor, 2014]) which figure prominently in accounts of children's everyday geographies. 
We find Neimanis's (2012) intra-active conceptualisation of water helpful in developing a language of smearings. Extending her analyses (and those of Pacini-Ketchabaw and Clark, 2016), we suggest that Neimanis's four 'hydro-logics' serve to animate the smearing-swarmingpercolating social-material processes described in the preceding and following sections. First, Neimanis (2012) considers water's communicative capacities; water can act as a medium or messenger, carrying dissolved or suspended particles, good news and bad. As we explore in the sections on and 'percolating', water has capacities to carry the seeping remains of decaying human bodies, bringing together different groups of bodies with in ways that trouble our understandings of social difference. Second, then, water can act as a source of differentiation. 'Water' is not only a globally-extensive, elemental puddle, but enables and constrains intraaction (Barad, 2007); 'smearing' is spatially extensive in this case study, but it is also often confined and channelled along particular watercourses and outdoor spaces (like playgrounds). Later, we discuss how, in this study, water was also central to percolating, narratives of racism, tempering further any romantic view of water (-as-life, or -as-cleanser). A third hydro-logic sees water act as archive - literally and/or metaphorically holding flotsam, rubbish, chemicals, bodies living and dead, binding mud particles, lubricating the passage of excrement within and outside animal bodies, acting as a container for oral histories, traditions, rodent life-cycled, and rumour. Finally, water is unknowable: it eludes our efforts to contain it - especially within languages and technologies. As we discuss in terms of 'percolating', while local children and adults seek to subject the watercourse to knowledge and narratives (which local stakeholders wold prefer to shush), its very fluidity and uncontrollability eludes that knowledge. In the following sections, we develop these arguments to signal how smearing-swarming-percolating are not only processually, cognitively and ontologically elusive, but are also entangled with/as difficult social-economic exclusions and ethico-political concerns, such as the classed, raced and religious geographies that surface through the following sections. 


\section{Swarming: rats}

For many children, the presence of rats was one symptom and characteristic of the community's

edgeland location (see Figure 3). Rats frequently featured in participants' accounts of outdoor

play/spaces (see Figure 4). Their proximity and omnipresence within designated playspaces

were highlighted as key concerns. Notably, participants often described the particular

'swarming' or 'creeping' quality of rats moving, not as individual creatures but elusively and

indivisibly en masse: rarely seen full-on but often briefly glimpsed, scurrying away, out of the

corner of one's eye. This 'swarming' shares some characteristics with 'smearing', but also

exhibits divergences. Swarming can also be theorised as both a noun and a verb: as a particular

mobility where rat populations feel like an undifferentiated, spatially extensive, thronging,

swelling rat-body, 'moving all the time'.

\section{Figure 3 On edge / coursing through}

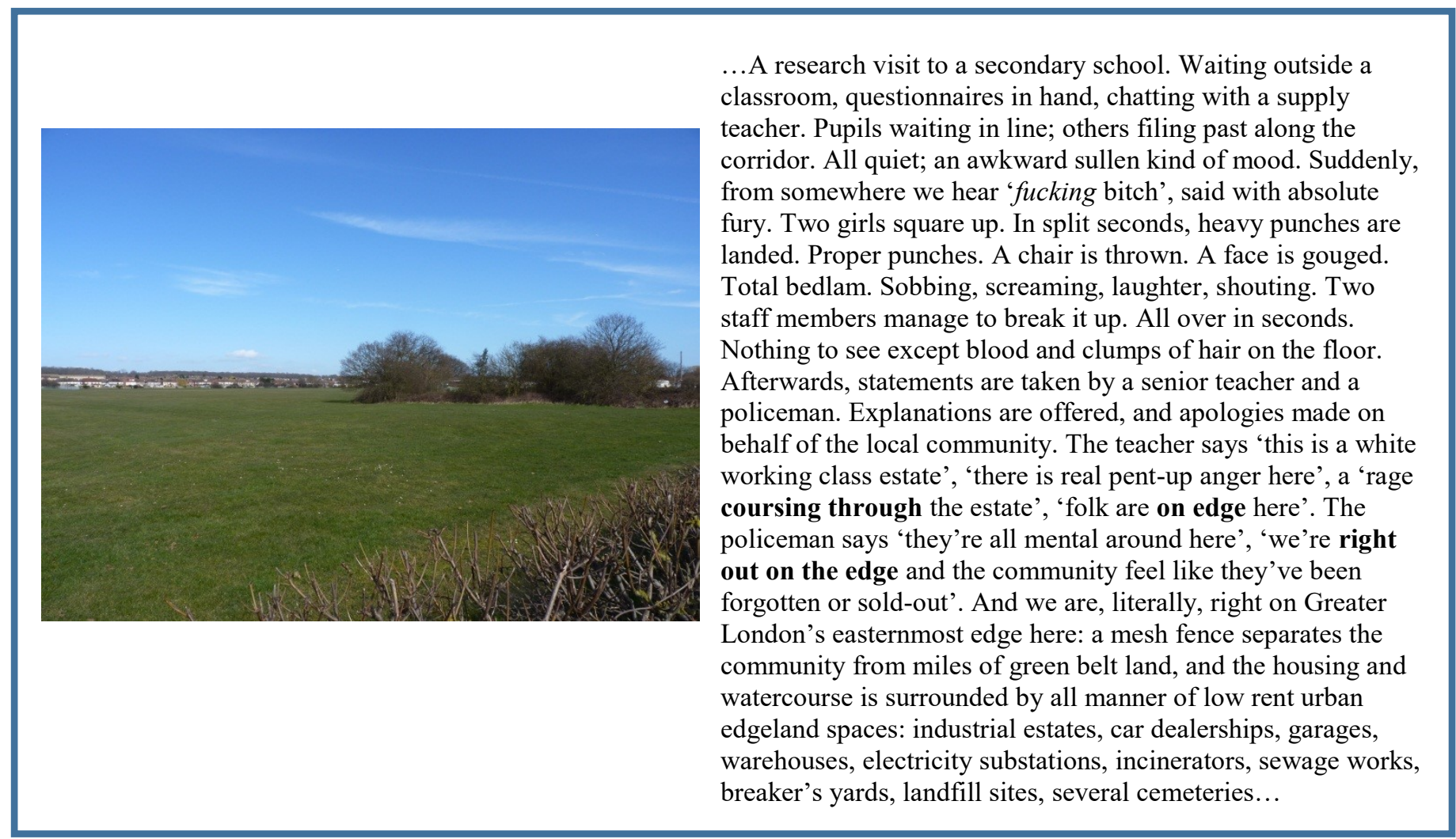




\section{Figure 4 Children and young people on rats}

"There are more rats in the park than children... They just don't care"

"People always dropping litter. So many rats. Always see rats"

"Dumped rubbish...causes visual pollution. There are always rats near us"

"Dissuade people from turning parks into rubbish dumps on summer weekends. The rats love it and swarm all over litter and remains of picnics"

"Rats are always 1 metre away. Can't always see but know they are near"

"Good place for landscape and wildlife - but dislike motorbikes, uncontrolled dogs and rats creeping around"

"What a horrible mess!! Gangs of rats make nests and the population grows"

"Saw rats eating out of bins here. Not nice"

"Make it so there is no litter. Rats are climbing on our play equipment"

"Too much rubbish. See rats moving all the time. Very creepy to see them on the slide"

"I want to take the rubbish out of the lake so rats won't be able to eat it"

"I feel strongly about cleanliness (chip shop papers, disposable containers from KFC, cans). Rats can cause disease and make the park look horrid"

"Rats could chase you and spread diseases"

"The park is too dirty - want to change people putting litter on the floor. Rats are very frightening for some people including little children and grandparents

"Rats can attack pet dog"

"Rats can bite and can eat eyes"

"Rat chased my little brother"

"Disgusting ratty place. Too many rats"

"Ratty playground. Just a disgrace. Nobody cares about it"

"OH MY GOD! Smelly bags that stink. Good place for rats"

"Filthy parks, litter, dog-mess...vandalism and yobs hanging around. I find it disturbing that rats inhabit our park",

"Skips are bad because older kids could get the stuff out of the skip and make rubbish and rats could live in there and breed more rats. Something should be done,",

"Nobody cleans the roads and they don't care about them. Only rats and teenagers hang out there"

"I would like my area to be clean with less rats and I would want the young people's behaviour to be better"

"Rats attracted by fly-tipping. Council should clean it up and make [this] a nicer place"

"No one cares that there is a rat problem"

Like 'poo', 'ratty'-ness was said to cover the playgrounds, play equipment and parks, 'always 1

metre away'. However, the process of 'swarming' was also characterised by an active,

uncontrollable elusiveness: rats as ever-present, yet agentically-avoiding presenting themselves.

Smearing and swarming thus described socio-materialities of divergent speeds/slownesses: rats

moved faster than mud, algae and 'assorted shit', with the latter being a more constant visual

presence and comprising stuff more readily touchable (though touching was to-be-avoided-at-

all-costs). The barely-apprehended movement and massing of rats, coupled with their

subterranean 'breeding' and 'nesting', was cause for significant alarm. 
The presence of rats was, again, also closely linked to the geography of watercourses and associated masses of waterlogged litter and 'poo', and sightings of rats near litter bins, watercourses or - especially - play equipment were often narrated with a sense of visceral anxiety. Many participants relayed (often narratively-dramatic) rat-related incidents and sightings, evoking a wide range of visceral threats posed by swarming rats (which could 'chase', bite eyes, spread 'plague'). Pets, young children and older residents were figured as especially vulnerable to murine attack or disease. Notably, in some instances, playspaces or play equipment were themselves described as rat-like or 'ratty', as if the 'swarming' rodent copresences were understood as characteristic, 'disgraceful' constituent features of their materialities. In describing the 'filthy', 'disturbing', 'ratty' (and, recall, poo-smeared) state of local playgrounds, participants again made discursive connections with the presence of older teenagers. On several occasions, participants labelled particular local playspaces as sites where ('only') rats and teenagers would 'hang out' (both were described as forming 'gangs'). As per discussions of 'assorted shit', the recurring narrative of 'they just don't care' - with implicit or explicit subtexts of coursing community marginality, disenfranchisement, anger, and feeling forgotten or 'sold out' - was never far from the surface.

Reflecting on these encounters, we recall recent (re)theorisations of urban natures and green spaces, which have often been underpinned by similar philosophical tenets to 'new waves' of childhood studies (Swyngedouw, 2006; Lachmund, 2013). A subset of this work has been concerned, specifically, with the potential for convivial urban political ecologies that are performative, emergent and more-than-human. For example Whatmore and Hinchliffe (2006:124) articulate an expanded, non-dualistic “conception of living cities" replete with pigeons and peregrine falcons, otters and fish, water voles and rats, plus manifold interventions designed to accommodate and conserve rarer species. More recently, a range of work (to which we return in our discussion of 'percolating') has argued for the largely progressive political potentialities of more-than-human 'encounters' towards convivial cities (Mayblin et al., 2016; Wilson, 2016; Lobo, 2016). These are figured as 'animated spaces', where “the urban landscape 
[is] sentient in its own right, as a hum of interacting humans and nonhumans that exceeds and performs its occupants" (Amin, 2015:239). Clearly, there exist controversies, confusions and complexities as to the relative 'worth' of the more-than-human constituents of a 'convivial' city. These tensions emerge not least where "ecological vernaculars", espoused and practiced by Other (human and/or nonhuman) urban inhabitants, are mobilised against the grain of expert policy-making, presaging "matters of controversy", resistance and "index[ing] a fraught political ecology" (Whatmore and Hinchliffe, 2006:134). And, as we acknowledge later, 'animated spaces' will not of necessity become 'convivial spaces', as social-materialities are drawn into multi-sited/scaled tensions and exclusions (Swanton, 2010).

In juxtaposing 'smearing' and 'swarming', we argue for greater attention to an alternative, perhaps supplementary, material-affective-sensory register of urban-ecological lives. We have witnessed just some of the largely undesirable (at least for children), atrophying, aesthetically (and otherwise sensorily) troubling socio-materialities of urban life in our case study community. These are, we suspect, not the kinds of urban lives that conservation charities or proponents of affirmative-redemptive accounts of childhood-natures would seek to celebrate. Thus, acknowledging 'smearing' and 'swarming' prompts us to think somewhat differently. Specifically, we are required to attend to the co-mingling of abject, undesirable matter-ings with urban political tensions. These politics are swept up in the undercurrents 'coursing through' our recollections from the school, our autethnographic reflections, and the children's quotations. These data bespeak a sense that the case study community is 'on edge' - that there is a roiling pressure, a marginality, a sense that 'they don't care about us' - that is materially, affectively and politically indivisible from smearings and swarmings in local playgrounds. In the final sections of the paper, we particularly highlight the intersecting politics of class, race and religion with, as and through socio-material processes in this community 


\section{From inter-sectionalities to extra-sectionalities?}

Although the case study community is changing demographically, it retains an identity as a 'white working class estate'. As we have begun to demonstrate, children's narratives of socialmaterial processes are indivisible from geographies of class, race and religion within this context, in ways which have seldom been articulated by studies of children's play or of contemporary intersectional urban social geographies. How, then, to reconcile, think and write the indivisibility of children's playful microgeographies and interrelated geographies of classed, raced and religious difference? Some of the most powerful, productive work on this kind of interrelation has been animated by the concept of 'intersectionality': a term originating in black feminist scholarship (Crenshaw 1991) - and latterly a multidisciplinary academic 'buzzword' (Davis 2008) - referring to "the simultaneous, intersecting, inseparable, coterminous and multiple forces of oppression acting on individuals/groups" (Chadwick 2017, p.2). This articulation of the intersectional-inseparable-coterminous constitutes an important prompt for considering the interconnectedness of, for example, class-race-religion within children's everyday, playful, material lives. However we would also make four reflections relating to the particular application of intersectionality within recent geographical scholarship.

First, we sympathise with recent critiques of the apparently apolitical, uncritical valorisation of vitalities in some nonrepresentational, posthumanist scholarship (including that on childhood), which can seem to imply vitalisms unhindered by social-political difference, power relations, or relative capacities of humans or nonhumans to move (or not) (Braun, 2005; Woodyer, 2016). Thus, some work in (particularly) nonrepresentational children's geographies has been critiqued for incessant attention to flows of bodies, materialities, affects and banalities are apparently decontextualixed, de-historicised and de-politicised (Mitchell and Elwood, 2012). While we would not necessarily agree that all such energies should be reduced or extrapolated to concerns with 'voice' or 'politics' (Kraftl, 2013), an intersectional critique that many theorisations of socialmaterialities could do more to acknowledge social-economic-political harms, violence and exclusions seems timely and unarguable (Hopkins and Pain, 2007, O’Neill Gutierrez and 
Hopkins, 2015). Moreover, we would argue that much geographical work predicated upon intersectionality could be brought into more productive conversations with theories of sociomaterialities.

However, second, we also note ongoing critiques of the deployment of intersectionality in some areas of scholarship. Staunæs (2003) argues, amongst others, that some studies of intersectionality have become both rather instrumental and a-political - treating different identity categories as a priori tick-boxes, which, differentially-arranged, effectively justify almost never-ending empirical studies of different differences. Intersectionality - or at least its pervasive application with the social sciences - has also been critiqued for constituting overly certain, clean, causal, linear, additive understandings of human life, shying away from the messy relationalities and intersubjectivities of lives-themselves (Horton and Kraftl, 2005, 2008). We argue that this particular, linear, additive application of intersectionality has proved unhelpful in apprehending the kinds of processual complex social-materialities and politics we have highlighted.

Third, we note that a range of work exists (notably within human geography) that has sought to expand how we theorise and research intersecting social differences - and especially ethnicities. Significantly, such studies do not always use the term 'intersectionality', choosing instead to engage with 'difference', 'multiculture', 'super-diversity' or 'conviviality'. What is persuasive about these diverse studies is that they offer a series of frames for understanding how social differences are produced in/through material, nonhuman, affective, nonrepresentational and/or embodied processes (Butcher, 2016; Bennett et al., 2016). Such multi-modal, multi-sensuous geographies re-ground the potentialities of anti-racist, postcolonial politics in the "signifying, mediating and presencing landscapes of belonging and identification" (Tolia-Kelly, 2010:11; also Noxolo and Preziuso, 2012). Other scholars articulate how, in diverse locales, material things and technologies are productive of tensions, dispositions and connections across difference (e.g. Swanton, 2010; Lobo, 2016). Perhaps most pertinently, we are inspired by 
Nayak's (2010) ethnographic work with a skinhead gang in a 'white, working class' English suburb (not dissimilar to our case study). He argues that - still - geographies of race and multiculture have neglected apparently 'ordinary' spaces of suburbia, focussing instead on spaces of 'thick urban interactions'. Nayak (2010:2370) thus seeks “a postcolonial geography of the suburbs [that] can be used as a circuit breaker to disrupt the affective 'chaining' of race to particular bodies, sites, and landscapes." Through ethnography and photography, he details how "mundane objects - clothes shops, bus stops, roads and lamp posts $-[\ldots]$ become transformed into the material canvas for expressions of race hatred" (Nayak, 2010:2374), offering mundane but powerful markers of exclusion towards non-white residents.

Fourth, then, each of these projects welcomes the nonhuman into overtly critical, politicised, studies of intersecting forms of power and social difference. However, we suggest that, vice versa, theorists of social-materialities could sometimes do more to accommodate discussions of the politics, harms, violence and indignities of multiple forms of socially-materially constituted exclusion and othering, retaining intersectionality's critical purchase, whilst simultaneously folding social-material complexities and vitalities into its theorisation. In response, and inspired in part by work exploring intersections of queer, critical race and posthumanist theories (Chen, 2012), we seek to open out an extra-sectional analysis that might be better attuned to the swarming-smearing-percolating social-materialities that figure in this paper.

We propose the term extra-sectionalities as offering a point of departure for witnessing the social-material processes that extend the ways in which age, class, ethnicity and religion are entangled. While 'extra-sectionality' has previously been used to describe "bonds formed between multiple, incommensurate positionalities, which at the limit need not be human" (Weiner and Young, 2011: 232), here we seek to significantly expand this concept to offer an account of social geographical differences intimately imbricated with/in and productive of social-materialities that are so common that they may be hidden-in-plain-sight. At this point, then, we list some of the possible work that the 'extra-' prefix might enable when conjoined 
with 'sectionalities', before engaging and substantiating these possibilities through further empirical analyses. One: extra-sectionalities afford an opportunity to formalise and articulate the co-constitution of social differences with/in nonhuman materialities and affects (including, perhaps, in some of the work cited above on urban multicultures). Two: more radically, the term implies, however, a broader conception of materialities than those generally admitted into work by childhood studies and other scholars. As Chen (2012) acknowledges, such 'animacies' challenge the languages that we have for characterising the intersections of (normative identity categories. And as Moore et al. (2003) argue, nonhumans may figure in the production of scientific or popular discourses through which social differences like race (in their work) are entangled with questions of environmental politics, stewardship and medicine. Yet, as discussed through this paper, processes like smearing-swarming-percolating are characterised by diverse sensory, spatial, temporal, performative and always-politicised registers of processuallycomplex socio-matter, hidden-in-plain sight. These contrast with (or extend beyond) the kinds of matter attended to by authors whose work we have reviewed in this section - not least in the sense that the materialities witnessed in Nayak's (2010), Chen's (2012) or Moore et al.'s (2003) work are of more obviously human making and are, arguably, more legible, coherent and meaning-ful than smearing-swarming-percolating. Three: amidst an incessant focus in new materialist literatures on 'entanglements' and relational thinking, we push further Nayak's (2010) call to focus on (effectively) 'thin' urban interactions by asking about the barelyrelational, barely-relate-able, barely-relating geographies of urban (non-)encounter that surfaced in and percolated through our data. In particular, we are interested in our own struggle to come to terms with our data, and in the troubling silences of the local Muslim community in what follows. Fourth: we ask whether and how the notion of extra-sectionalities might afford an opportunity to re-think how to respond, ethically and politically, to the kinds of social-materities and marginalisations that percolate through the final sections of the paper. 


\section{Percolating: poison, distrust and 'racist groundwater'}

Figure 5 Undercurrents

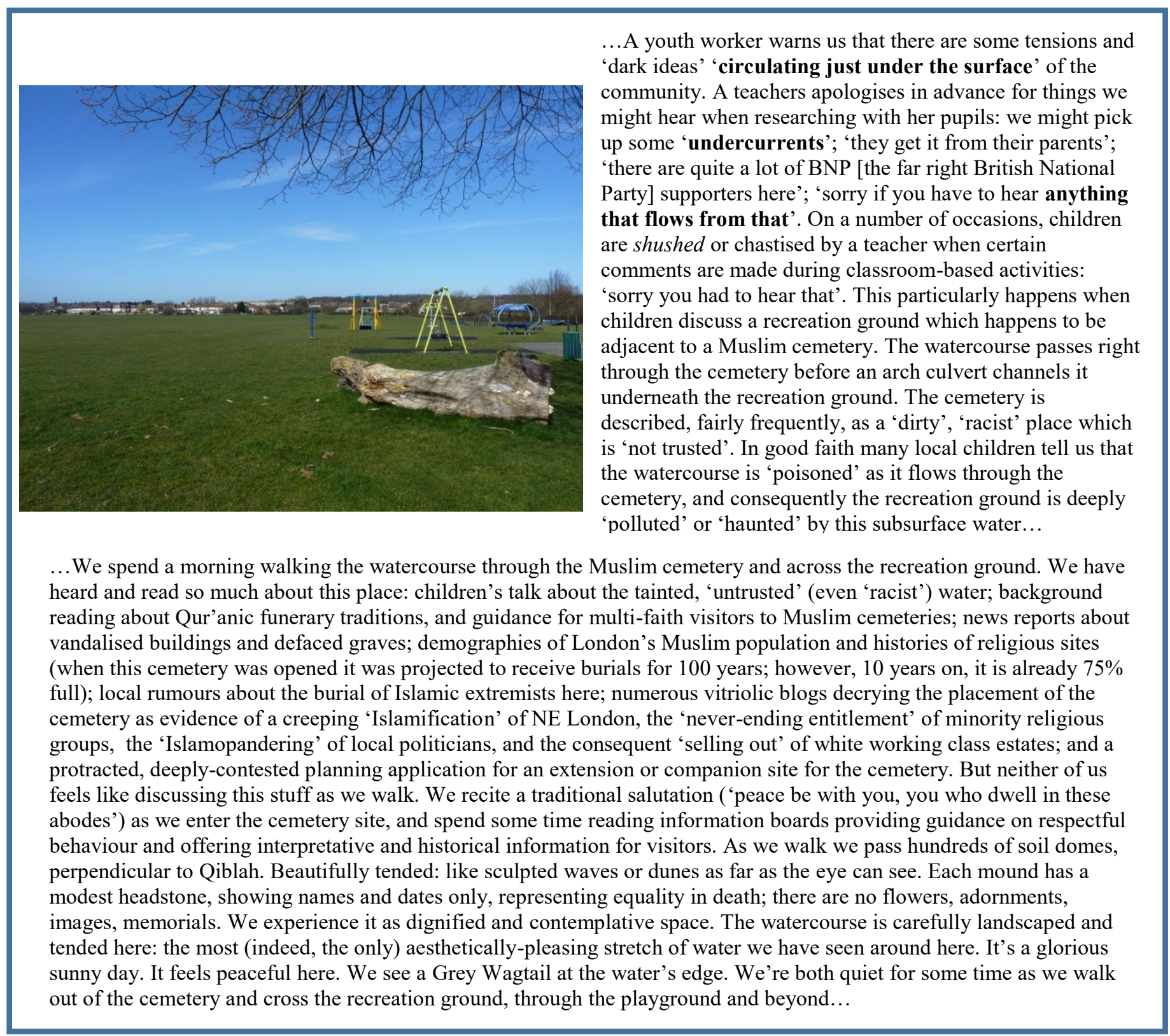


Figure 6 Children and young people on groundwater

"Groundwater is poisonous"

"Don't trust. The water is racist"

"Skate park is polluted"

"Worrying place. Soil is poisoned"

"Dirty and smelly place. Very polluted"

"Don't trust this place. Park is poisoned"

"By Muslim cemetery - don't trust it"

"DON'T TRUST. Dirty and racist place"

"Near graveyard - Islam"

"Muslims in our community. Don't trust"

"Don't trust the water because ISLAM"

"Muslim graves pollute the water"

"Water from Islam"

"Water of Islam flows here"

"Water percolates from cemetery"

"Pollution and dirt flows into rec"

"Stream [from cemetery] is infectious and pollutes rec"

"Heal the community"

"MORE PEACE. NO MORE RACISTS"

One of the community's largest designated playspaces is adjacent to, and downstream from, a

Muslim cemetery. For over a decade, we have been troubled by the quotations in Figure 6 , which narrate this section of the watercourse. These data have evoked in us - and in audiences with whom we have shared them - a visceral, troubled, emotive set of responses. These narratives of water flowing through the cemetery and under the recreation ground were offered, apparently in good faith, by participants who were enthusiastic, good-natured and engaged in our research. These narratives of 'poisoned', 'haunted', 'dirty', 'polluted', even 'racist' water surfaced in spite of adult professionals' diligent attempts to shush, pre-empt or chastise them (see Figure 5). Objectively, these narratives appear to be a caustic mix of parental discourses of the cemetery as an 'unknown', 'untrusted 'no go' area, community rumours about Muslim burial practices and peer group urban myths about hauntings, underpinned by various brands of anti-Muslim sentiment in local media, online and political discourse. Thus water percolating through the cemetery was figured as contaminated and abject. Moreover, it was imbued with a kind of character or agency: having the capacity to harm, haunt or frighten; being dispositionally 'racist'. The cemetery - and groundwater allegedly 'poisoned' by it - appeared 
to be figured as 'racist' insomuch as it was perceived as an inscrutable, antagonistic, Other affront to this 'white, working class' community. For these children, the groundwater was considered somehow materially and imaginarily 'polluted' by Islam as a result of flowing though the cemetery. This, in turn, made it seem 'racist' to them: mirroring and significantly extending local media, online and political discourses which variously depict the 'Islamification' of communities as invasive, unsettling, forceful and antithetical to 'white, working class' identities (thereby, in some versions of this discourse, 'anti'-'white, working class', therefore 'racist'). We have struggled to some to terms with these challenging naratives in which children calmly othered particular local residents and landmarks in ways that seemed to us to be overtly and obviously racist, yet also deployed the term 'racist' as an accusatory adjective against those same people and spaces. This seemed to us to be bizarre and kind of staggering in its slow discursive violence.

Notably, Muslim children responded to these narratives with silence. Although they participated generously and enthusiastically in research activities (beautifully evoking local dirt/poo/litter, as well as co-present ducks, foxes, graffiti, and urban myths that are beyond the bounds of this paper [see Horton and Kraftl, 2017]) they actually disclosed nothing about the cemetery in their contributions. Not one Muslim participant made mention of this space in their individual survey responses; these participants politely declined to reply to our prompts on this topic, and kept their own counsel when group discussions turned to the cemetery. Starkly, though, our survey data show that Muslim children in this community were, at all ages, much more likely to experience bullying, much more anxious about spending time outdoors near their home, and much less likely to visit local playspaces and leisure venues than white British peers.

In the space between these silences - the shushed comments of some participants and the polite, marginalised nondisclosivity of others - Figure 6 suggests a constellation of lay geologies and hydrologies, rumours and myths, feelings and tensions (being 'on edge'), matter and sociality. These data cannot be understood in isolation from the socio-materialities witnessed in the 
preceding sections. But how to find a way of thinking and writing - of responding - that acknowledges both the complex, murky, massy, local social-material processes of smearingswarming-percolating and the stark deeply troubling classed, ethnic and religious exclusions which are starkly co-present in children and young people's narratives of play? (And, let us not forget, these upsetting, painful, politicised narratives emerged via discussions of the supposedly inherently affirmative, joyful, wholesome topic of outdoor play). The notion of 'extrasectionalities', schematised in the previous section, provides a theoretical language through which we might make sense of (or at least better witness) the complex, contradictory, challenging nature of such data. Based upon this theorisation, we would propose a number of responses to 'percolating', which as well as problematising children's narratives, exclusions and racisms, juxtapose a series of considerations that are intended to provoke further, productive debate.

Our first response to participants' accounts of 'percolating' (re)centres upon a theorisation of water-itself. Water is being perceived to operate here as a medium for differentiation (Neimanis, 2012). Water is felt, expressed, materialised and articulated in different ways in/through different bodies of water (in this case, a distant tributary of the Thames). Water is "teeming below and seeping through and across our surfaces, as differentiator and connector of our meaningful interbeing” (Neimanis, 2012:166). As Gandy (2006) shows, water has (bio)political connotations: in contemporary cities, problems with water exemplify urban injustices, articulating questions of geopolitics, colonialism and modernity (also Pacini-Ketchabaw and Clark, 2016). Water is thus "inherently political, not only because it is an object of conventional politics, but also because of its material imbrication in the socio-technical formations through which political processes unfold" (Bakker, 2012:618). Yet, compared with these latter characterisations of watery politics, (and, for instance, the work of Chen [2012] or Moore et al. [2003]), our examples are not explicitly tied to the governance of water, its representational environmental politics nor its capacity as a resource. The politics at/of play here are, we suggest, extra-sectional in the sense that they are speculative, excessive, elusive - forging rumoured, 
tenuous, subsurface connections between questions of race and religion and the 'pollutants' 'contained' within water.

Second, reflecting on Figure 6, we find both inspiration and frustration with/in recent posthuman, new materialist and/or postcolonial work that has attempted to theorise entanglements of ethnicity, colonialism and nonhuman materialities. Much of this work articulates alternative and, often, quite hopeful languages and ontologies for reconsidering how humans might relate to the earth. For instance, in work on early childhood, Pacini-Ketchabaw et al. (2011) conceive of 'race' as an event - as capricious, event-al, an assemblage of materialities, affects and discourses that work in a "chain of contingency" (Saldhana, 2006:18). Through observational work at meal-times in Canadian early childhood settings, they ask how "are the tables, plastic chairs, metal spoons, and their configurations in the room all active participants in food-eating practices as colonial acts?" (Pacini-Ketchabaw et al., 2011:29). On one hand, we seek to mobilise similar diffractive, interruptive readings that juxtapose everyday socio-materialities with/in questions of race - attempting to provide a sense of these questions through our figural re-presentation of data. Yet we are ambivalent about where 'racisms' are located in the social-materialities of our examples and, in contrast, can be less sure that our diffractive readings can actually "make our data stutter against racisms" (Pacini-Ketchabaw et al., 2011:29). On the other hand, and very much related, Pacini-Ketchabaw et al. (2011) characterise race-assemblages as encounters. Their work again resonates with work on 'contact zones' (Taylor et al., 2012), wherein there is an obvious encounter - whether embodied and/or materially-mediated - between bodies marked out by difference ethnicities (also Nayak, 2010). For example, describing encounters between indigenous and settler Australians, climate, the ocean, dangerous jellyfish and crocodiles, Lobo (2014:101) argues that "[t]hese energies entangle sensuous bodies with the richness of a more-than-human world and have the potential to offer new insights into exploring how racially differentiated bodies live with difference". She, too, valorises speculative, artistic approaches (also Taylor et al., 2012) through which it might be possible to understand 'whiteness' as one (albeit dominant) force in public life, and through 
which affirmative, "alter-racist futures" maybe imagined in which bodies human and nonhuman become-otherwise (Lobo, 2016: 70), formulating affective and potentially affirmative connections across social cleavages (Noxolo and Preziuso, 2012).

However, in the context of our study, we are unsure about languages that presume some kind of embodied, co-present, materialised encounter, connection or relationality will necessarily constitute more progressive convivialities. The kinds of (smearing-swarming-percolating) processes and politics foregrounded here are much more dispersed, processually-complex, divergent and illegible than neater theorisations of encounter or intersectionality tend to allow. It is hard to find a position from which to write when dealing with elusive, subsurface processes, and plural co-constituted discourses, angers, undercurrents and silences, all hidden-in-plainsight. So we ask how might (or should) we respond when entanglements of children, play, and nonhuman 'natures' offer up troubling accounts of socio-materialities, harmfully and painfully indivisible from classed, racialized, aged, gendered marginalisations?

For us, such questions again suggest the extra-sectionalities of life. For, in one sense, it appears that it is the elision of religion/race, with the elusive, percolating, 'unknowable' properties of water, and with the discomfort prompted by our bodily finitude (the cemetery), which seemed so powerful. In another sense, the Muslim community is a more-or-less absent presence here. Participants' accounts of the cemetery and its groundwater did not disclose direct encounters between Muslims and non-Muslims; nor the overt markers of race or exclusionary moments that Nayak (2010) so brilliantly captures. Rather, it was through encounters with, and imaginaries of, percolating that community anxieties about religion, marginalisation and 'others' were manifest.

However, in adding further complexity, we recognise local communities' right to critically question planning and policy decisions which result in the siting of contentious land-uses (including cemeteries, and the landscape evoked in Figures 3 and 5) in and around marginal/ised neigbourhoods. But we are left to wonder: why should the siting of this cemetery - which we 
found to be a peaceful, attractive, non-intrusive place, explicitly open to all visitors - matter so much that children raised it, via profoundly troubling 'undercurrents' - in a study about play? Why should the critical questioning of planning decisions necessarily be connected with a sense that the groundwater 'is racist'?

Our reflections on these data suggest many future research directions (notably further research with the cemetery itself, and with local Muslim communities). However, our focal interest here is why and how this matters to these young people. How are young people's feelings of being left behind, on edge, entangled with forms of frustration and powerlessness at decisions imposed from beyond? Moreover, whilst we would classify many of their statements as racist, we note an apparent disjuncture between the toxic content of their talk and the calm, friendly, helpful character of their participation in our research, even as they told us, in-good-faith that the cemetery is racist, that the groundwater itself is racist, and that they are victims of these flows. The smearing-swarming-percolating lay knowledges, rumour, lay narratives of matter, nature, hydrology, and water-based wildlife/processes, dirt/disgust, death, and play, victimhood and marginalisation, and concerns about lack of consultation over the cemetery's location and a range of other recent planning applications are indivisible in the production of these extrasectional narratives.

\section{Conclusions}

This paper - and the analyses contained herein - was developed through a decade-long conversation between a large, troubling dataset and slowly-emerging conceptual work in nonrepresentational, posthuman, 'new wave' childhood studies. In this regard, one contribution of this paper has been to question, retheorise and evidence alternative sets of socio-material processes that, because they are 'hidden-in-plain-sight', uncategorisable, massy, messy and processual, tend to go overlooked in virtually all studies of childhood. Plainly, in recounting these smearing-swarming-percolating politics we find ourselves far from the idealisations of children's outdoor play, affirmative encounters with companionable nonhumans, and singular 
meaning-ful encounters with material culture which characterise so much extant work in this area. Whilst exceptional work has connected posthumanist theorising with questions of indigeneity through ethnography and art (e.g. Taylor, 2012; Pacini-Ketchabaw and Clark, 2016), much other work inspired by the same philosophical lineages has tended to skirt around questions of social difference, power and politics (Mitchell and Elwood, 2012).

We would argue that this paper makes a series of wider contributions, both within and beyond childhood studies and children's geographies. Firstly, we have sought to draw out particular, important registers of socio-materialities - namely smearing-swarming-percolating - that have often been overlooked in geographical and other scholarship inspired by theorisations of matter, nature and nonhuman co-presences. We have articulated socio-materialities that are at once: noun-al and verb-al; that may induce discomfort or nausea; that exceed nameable, defineable 'objects' or 'actants' (even if constituted always-already in-relation); that are, consequently, messy, massified, festering, oozing and pressing on (social) life; and that co-constitute morethan-social geographies and exclusions - some of which may be immediately evident, but some of which become more poignantly evident in/through narratives of smearing-swarmingpercolating. We argued that recent theorisations of water provide a provisional framework towards a language of coagulative, oozing socio-materialities, yet sought to extend these accounts through the additional and admixed forms of socio-materiality evident in smearingswarming-percolating.

Secondly, we have developed a suite of methods and, particularly, modes of analysis and presentation that might enable other scholars to witness the social-materialities of smearingswarming-percolating. These methods - questionnaires, mapping, autoethnography - were not particularly novel in themselves. Rather, we experimented with ways of analysing and presenting questionnaire and mapping data that are usually 'coded' and reduced to 'indicative' quotations. We did so both by presenting such data as 'lumps' in order to afford a sense of the massy, pressing, spatially-extensive social-materialities of smearing-swarming-percolating; and 
by juxtaposing these data with observations and autoethnographic accounts in order to grapple with some of the troubling complexities of marginalisation, class, race and religion bound up with and through smearing-swarming-percolating.

Thirdly, although initially not planning to intervene into debates about multiculturalism, conviviality and cosmopolitanism, we have sought to bring these literatures into a different kind of conversation with socio-materialities. Although inspired by recent work on landscape, materiality, affect, embodiment and race, we have also critiqued some hesitation around that work - and of work on intersectionalities - as we attempted to think how multiple forms of social identity (such as those felt by 'white, working class' children) are compounded in/through socio-materialities. Indeed, we have reflected that we would not been so acutely aware of community geographies of exclusion and marginality had we not been so haunted by the processes of 'smearing', 'swarming' and 'percolating' that seemed to matter, so profoundly, that children raised them in a study about their play.

Our discussions of extra-sectionalities are intended as a way to both acknowledge but also think on from previous work on intersectionality and materiality. We argued that extra-sectional theorising might: enable understandings of the co-constitution of intersecting social differences with/in nonhuman materialities and affects; permit an expanded conception of the kinds of materialities that should be considered in accounts of social-political geographies of communities - particularly accommodating those materialities that are harder to categorise, that are less obviously produced by human hands as 'markers' of exclusion or discrimination, and that are hidden-in-plain-sight; further push calls to focus away from 'thick' urban interactions by emphasising (non-)events of encounter, in which narratives of social-material process are instrumental in constituting social and community otherness; suggest new ways of collecting and presenting research 'data'; and prompt us to raise a whole series of questions about how ethically, politically and conceptually - we might come to terms with the kinds of feelings articulated by children about, in this case study, smearing-awrming-percolating. In so doing, we 
hope that the paper provides new provocations, languages, and some resonances (and

dissonances) that may enable future scholars to conceive how messy, massy, murky

materialities are articulated with/in social, ethical and political tensions that matter.

\section{Acknowledgments}

This paper is dedicated to the memory of Stuart Lester and Lisa Procter: two dearly missed colleagues whose theorisations of childhood play have inspired our work here and everywhere.

We thank all of the children, young people and adults who took part in our research and the schools and youth groups which supported the project. We also thank colleagues who collaborated on the wider project of which this research was part, including Hugh Matthews, John Barker, Richard Davey, Elodie Marandet, Michelle Pyer and Fiona Smith. We are grateful for feedback from audiences at the Association of American Geographers Annual Meeting, Centre for the Study of Childhood and Youth International Conference, the Education and Social Research Institute at Manchester Metropolitan University, as well as Geoff Darwin. Many thanks to Kate Derickson and three anonymous referees for such generous and supportive comments on an earlier draft.

\section{References}

Amin A (2015) Animated space. Public Culture 27(2):239-258.

Änggård E (2010) Making use of 'nature' in an outdoor preschool: classroom, home and fairyland. Children, Youth and Environments 20(1):4-25.

Änggård E (2016) How matter comes to matter in children's nature play: posthumanist approaches and children's geographies. Children's Geographies 14(1):77-90.

Bakker K (2012) Water: political, biopolitical, material. Social Studies of Science 42(4):616-623.

Barad K (2007) Meeting the Universe Halfway. Durham:Duke University Press.

Bennett K, Cochrane A, Mohan G, and Neal S (2016) Negotiating the educational spaces of urban multiculture: skills, competencies and college life. Urban Studies

Braun B (2005) Environmental issues: writing a more-than-human urban geography. Progress in Human Geography 29(5):635-650.

Butcher M (2016) Reimagining home: visualizing the multiple meanings of place. In:Nairn K, Kraftl P and Skelton T (eds) Space, Place, and Environment. Singapore: Springer,pp.293-310.

Carter S. Kirby P and Woodyer T (2016) Ludic - or playful - geopolitics. In:Benwell M and Hopkins P (eds) Children, Young People and Critical Geopolitics. Farnham: Ashgate,pp.61-73.

Chen M. (2012) Animacies: Biopolitics, racial mattering, and queer affect. Durham:Duke University Press.

Cole-Hamilton I, Harrop A and Street C (eds) (2002). Making the Case for Play. London:National Children's Bureau.

Cross G (1999) Kids' Stuff. Boston:Harvard University Press.

Derevenski J (ed) (2000) Children and Material Culture. London:Routledge.

Gandy M (2006) Water and landscape. Landscape Research 31(2):117-119.

Häkli J and Kallio K (2016) Theorizing children's political agency. In:Skelton T and Aitken S (eds) Establishing Geographies of Children and Young People. Singapore:Springer,pp.

Harker C (2005) Playing and affective time-spaces. Children's Geographies 3(1):47-62.

Hopkins P and Pain R (2007) Geographies of age: thinking relationally. Area 39(3):287-294.

Horton J and Kraftl P (2005) What else? Some more ways of thinking about and doing children's geographies. Children's Geographies 4(1):69-95.

Horton J and Kraftl P (2008) Reflections on geographies of age. Area 40(2):284-288.

Jones O (2013) Re-thinking and re-connecting communities with and through water issues. Report, Bath Spa University, UK.

Jones O (2015) 'Not promising a landfall...': an autotopographical account of loss of place, memory and landscape. Environmental Humanities 6(1):1-27. 
Kernan M (2010) Outdoor affordances in early childhood education and care settings: adults' and children's perspectives. Children, Youth and Environments 20(1):152-177.

Kraftl P (2013) Beyond 'voice', beyond 'agency', beyond 'politics'? Hybrid childhoods and some critical reflections on children's emotional geographies. Emotion, Space and Society 9:13-23.

Lachmund J (2013) Greening Berlin. Boston:MIT Press.

Lester S and Maudsley M (2007) Play, Naturally. London:Play England.

Lobo M (2014) Everyday multiculturalism: catching the bus in Darwin, Australia. Social and Cultural Geography 15(7):714-729.

Lobo M (2016) Co-inhabiting public spaces: diversity and playful encounters in Darwin, Australia. Geographical Review 106(2):163-173.

Marion G and Nairn A (2011) 'We make the shoes, you make the story'. Teenage girls' experiences of fashion, bricolage and narrative identity. Consumption, Markets and Culture 14(1):29-56.

Mayblin L, Valentine G and Andersson J (2016) In the contact zone: engineering meaningful encounters across difference. Geographical Journal 182(2):213-222.

Melson G (2005) Why the Wild Things Are: Animals in the Lives of Children. Boston:Harvard University Press.

Mitchell C and Reid-Walsh J (2002) Researching Children's Popular Culture. London:Routledge.

Mitchell K and Elwood S (2012) Mapping children's politics: the promise of articulation and the limits of nonrepresentational theory. Environment and Planning D 30(5):788-804.

Morrow V (1998) My animals and other family: children's perspectives on their relationships with companion animals. Anthrozoos 11(4):218-226.

Nayak A (2010) Race, affect, and emotion: young people, racism, and graffiti in the postcolonial English suburbs. Environment and Planning A 42(10):2370-2392.

Neimanis A (2012) Hydrofeminism: or, on becoming a body of water. In:Gunkel H, Nigianni C and Soderback F (eds) Undutiful Daughters. New York:Palgrave, pp.85-100.

Noxolo P and Preziuso M (2012) Moving matter. Interventions 14(1):120-135.

O’Neill Gutierrez C and Hopkins P (2015) Introduction: young people, gender and intersectionality. Gender, Place and Culture 22(3):383-389.

Pacini-Ketchabaw V and Clark V (2016) Following watery relations in early childhood pedagogies. Journal of Early Childhood Research 14(1):98-111.

Pacini-Ketchabaw V, Nxumalo F and Rowan C (2011) Nomadic research practices in early childhood: interrupting racisms and colonialisms. Research Methodology 2(1).

Philo C (2000) 'The corner stones of my world'. Childhood 7(3):243-256.

Philo C (2016) 'Childhood is measured out by sounds and sights and smells, before the dark hour of reason grows': Children's Geographies at 12. Children's Geographies 14(6):623-640.

Philo C and Swanson K (2008) Afterword: global portraits and local snapshots. In:Jeffrey C and Dyson J (eds) Telling Young Lives. Philadelphia: Temple University Press,pp.193-208.

Prout A (2005) The Future of Childhood. London:Routledge.

Rautio P (2013a) Children who carry stones in their pockets: on autotelic practices in everyday life. Children's Geographies 11(4):394-408.

Rautio P (2013b) Being nature: interspecies articulation as a species-specific practice in relating to environment. Environmental Education Research 19(4):445-457.

Rautio P and Jokinen P (2016) Children's relations to the more-than-human world beyond developmental views. In: Evans B, Horton J and Skelton T (eds) Play and Recreation, Health and Wellbeing. Singapore: Springer,pp.35-50.

Russell R and Tyler M (2005) Branding and bricolage: gender, consumption and transition, Childhood 12(2):221-237.

Saldhana A (2006) Reontologising race: the machinic geography of phenotype. Environment and Planning D 24(1):9-24.

Skelton T (2013) Children, young people and politics: transformative possibilities for a discipline. Geoforum 49:4-6.

Staunæs D (2003) Where have all the subjects gone? Bringing together the concepts of intersectionality and subjectification. Nordic Journal of Feminist and Gender Research 11(2):101-110.

Swanton D (2010) Sorting bodies: race, affect, and everyday multiculture in a mill town in northern England. Environment and Planning A 42(10):2332-2350.

Swyngedouw E (2006) Circulations and metabolisms:(hybrid) natures and (cyborg) cities. Science as Culture 15(2):105-121.

Taylor A (2013) Reconfiguring the Natures of Childhood. London:Routledge.

Taylor A (2014) Settler children, Kangaroos and the cultural politics of Australian national belonging. Global Studies of Childhood 4(2):169-182. 
Taylor A and Pacini-Katchabaw V (2015) Learning with children, ants and worms in the Anthropocene: towards a common world pedagogy of multispecies vulnerability. Pedagogy, Culture and Society 23(4):507-529.

Taylor A, Pacini-Katchabaw V and Blaise M (2012) Children's relations with the more-than-human world. Contemporary Issues in Early Childhood 13(2):81-85.

Tipper B (2011) 'A dog who I know quite well': everyday relationships between children and animals. Children's Geographies 9(2):145-165.

Tolia-Kelly D (2010) Landscape, Race and Memory. Farnham:Ashgate.

Whatmore S and Hinchliffe S (2006) Living cities: towards a politics of conviviality. Science as Culture $15(2): 123-138$

Wilson H (2016) On geographies of encounter: bodies, borders and difference. Progress in Human Geography online early.

Woodyer T, Martin D and Carter S (2016) Ludic geographies. In: Evans B, Horton J and Skelton T (eds) Play and Recreation, Health and Wellbeing. Singapore:Springer,pp.17-34. 